\title{
The Mycoparasite Ampelomyces quisqualis Expresses exgA Encoding an exo- $\beta-1,3-$ Glucanase in Culture and During Mycoparasitism
}

\author{
Yaniv Rotem, Oded Yarden, and Abraham Sztejnberg
}

\begin{abstract}
First, second, and third authors: Department of Plant Pathology and Microbiology, Faculty of Agricultural, Food and Environmental Quality Sciences, The Hebrew University of Jerusalem, Rehovot 76100, Israel; second author: The Otto Warburg Center for Agricultural Biotechnology, The Hebrew University of Jerusalem, Rehovot 76100, Israel.
\end{abstract}

Accepted for publication 11 May 1999.

\begin{abstract}
Rotem, Y., Yarden, O., and Sztejnberg, A. 1999. The mycoparasite Ampelomyces quisqualis expresses exgA encoding an exo- $\beta-1,3$-glucanase in culture and during mycoparasitism. Phytopathology 89:631-638.

Ampelomyces quisqualis, a mycoparasite of fungi causing powdery mildews, exhibited high levels of extracellular exo- $\beta-1,3$-glucanase activity in culture compared with Neurospora crassa and Gliocladium roseum. A. quisqualis culture filtrates affected powdery mildew caused by Sphaerotheca fusca in a manner indicative of cell wall degradation, as deter-

identity with amino acid sequences of Trichoderma harzianum exo- $\beta-1,3-$ glucanase and Cochliobolus carbonum EXG1 (both encoding exo- $\beta-1,3-$ glucanase) and T. harzianum bng13.1 (encoding an endo- $\beta-1,3$-glucanase), respectively. The $\operatorname{exg} A$ gene had a predicted molecular mass of $84 \mathrm{kDa}$ and a pI of 4.79. The gene was expressed during the late stages of growth in culture, and transcription was induced by fungal cell wall components. Transcript levels for $\operatorname{exgA}$ were present during late stages of hyperparasitism and were abundant along $A$. quisqualis mycelium and were slightly less abundant in A. quisqualis pycnidia.
\end{abstract} mined by microscopic examination. A gene encoding an exo- $\beta-1,3$-glucanase in A. quisqualis, designated exgA, was isolated and sequenced. The predicted polypeptide deduced from $\operatorname{exgA}$ had 46, 42, and $30 \%$
Additional keywords: lytic enzymes.
Ampelomyces quisqualis Ces. is a mycoparasite of many fungal species that cause powdery mildews (17). The mycoparasite infects and forms pycnidia inside fungal hyphae, conidiophores, conidia, and cleistothecia (8). Cells of the mycoparasite grow normally inside host cells, in spite of gradual degeneration of host cells (9).

$\beta-1,3-$ Glucanases have been identified and studied in fungi, bacteria, actinomycetes, algae, mollusks, and higher plants (13). In fungi, $\beta$-glucanase activity has been found in most isolates examined (13). Various putative functions have been assigned to fungal $\beta$ glucanases, including metabolic, morphogenetic, and ecological functions (13). One example of a possible ecological role played by these enzymes is their involvement in the interaction between species of the mycoparasite Trichoderma and its host, Sclerotium rolfsii; high amounts of $\beta$-1,3-glucanase and chitinase have been detected in dual cultures of T. harzianum and Sclerotium rolfsii (7). Penicillium purpurogenum is another antagonist that produces $\beta$ 1,3-glucanase. The enzymatic complex of $P$. purpurogenum attacks the mycelium of its host, Monilinia laxa, causing lysis of hyphae and spores (10). Studies on Schizophyllum commune mycoparasitism in a dual culture with its host, Rhizoctonia solani, revealed that the main enzyme detected in cultures was endo- $\beta-1,3(4)$-glucanase; the activity of this enzyme was enhanced markedly compared with cultures of the mycoparasite alone (5). $\beta$-1,3-Glucanase of Tilletiopsis spp. has been suggested as a potential component of the biocontrol action of this yeast against powdery mildew (19).

Some fungal $\beta$-1,3-glucanases are produced constitutively, whereas production of others is regulated. Regulation mechanisms include induction and catabolite repression (13). Little is known about extracellular enzymes of $A$. quisqualis. However, it has been established that in vitro A. quisqualis constitutively produces several extracellular enzymes, among them a $\beta$-1,3-glucanase (12).

Corresponding author: A. Sztejnberg; E-mail address: abraham@agri.huji.ac.il

Publication no. P-1999-0615-01R

(C) 1999 The American Phytopathological Society
Genes encoding $\beta$-1,3-glucanases from various organisms, including plants, bacteria, and yeasts have been isolated and characterized (6). However, to date such genes have been isolated only from two filamentous fungi. The EXG1 gene of the filamentous plantpathogenic fungus Cochliobolus carbonum, encoding exo- $\beta-1,3-$ glucanase, has been isolated, following the determination of the partial amino acid sequence of the purified enzyme (15). A gene encoding an endo- $\beta-1,3$-glucanase of the mycoparasite $T$. harzianum has been cloned and sequenced. Its structural analysis suggests that its endo- $\beta$-1,3-glucanase contains a hydrophobic leader peptide that may be cleaved by an endoproteinase (6).

In this paper, we report on some of the characteristics of $A$. quisqualis exo- $\beta-1,3$-glucanases and the isolation and expression of the A. quisqualis exgA gene encoding an exo- $\beta$-1,3-glucanase.

\section{MATERIALS AND METHODS}

Fungal isolates and growth conditions. Isolate 10 of A. quisqualis was used. The isolate was maintained on bran extract agar medium (water-boiled, cheesecloth-filtered extract of $100 \mathrm{~g}$ of bran, $20 \mathrm{~g}$ of malt extract [Difco, Detroit, MI], $2 \mathrm{~g}$ of DL-asparagine, $0.25 \mathrm{~g}$ of chloramphenicol, and 1 liter of deionized water) (17).

Strain 74-OR23-1A(FGSC987) of Neurospora crassa Shear \& Dodge and isolate 2479 of Gliocladium roseum (Link) Bainier used in this study were from the fungal collection of the Department of Plant Pathology and Microbiology, The Hebrew University, Rehovot, Israel.

The liquid medium used to study glucanase production was potato broth (PB) containing water-boiled, cheesecloth-filtered extract of $200 \mathrm{~g}$ of PB per liter of deionized water. A pycnidiospore inoculum of $A$. quisqualis was prepared by flooding 3-week-old fungus cultures grown on solid bran extract medium with sterile water and collecting the spore suspension. For glucanase production, $A$. quisqualis was grown in a 2-liter fermentor (MultiGen, model F2000, New Brunswick Scientific Co., Edison, NJ) inoculated with $2 \times 10^{5}$ spores per $\mathrm{ml}$ of medium. During growth, the aeration rate 
was 1 liter of air per min per liter of medium, agitation speed was $180 \mathrm{rpm}$, and temperature was maintained at $25^{\circ} \mathrm{C}$. Samples were taken daily and assayed for enzyme activity. PB medium, amended with glucose at $20 \mathrm{~g} /$ liter (potato dextrose broth, $\mathrm{PDB}$ ) was used to obtain the fungal biomass used for DNA extraction.

To compare the $\beta$-1,3-glucanase activity in culture filtrates of $A$. quisqualis to the activity in cultures of $N$. crassa and G. roseum, the fungi were grown on nutrient yeast dextrose broth medium $(8 \mathrm{~g}$ of nutrient broth [Difco], $5 \mathrm{~g}$ of yeast extract [Difco], $10 \mathrm{~g}$ of D-glucose, and 1 liter of deionized water). Inoculum consisted of $1 \times 10^{5}$ conidia per ml. The fungus was grown in 100-ml flasks containing $30 \mathrm{ml}$ of medium at $120 \mathrm{rpm}$ on an orbital shaker (New Brunswick Scientific) at $25^{\circ} \mathrm{C}$. For experiments in which dry fungal mycelium was added to the medium, A. quisqualis was grown in 100-ml flasks containing $30 \mathrm{ml}$ of Vogel's medium (20) containing $1.5 \%$ sucrose and $0.2 \mathrm{mg}$ of lyophilized $N$. crassa mycelium per $\mathrm{ml}$.

To examine the effect of $A$. quisqualis culture filtrate on powdery mildew caused by Sphaerotheca fusca (Fr.) Blumer, A. quisqualis was grown in 100-ml flasks containing $30 \mathrm{ml}$ of PB medium. Inoculum consisted of $3 \times 10^{5}$ conidia per $\mathrm{ml}$, and the fungus was grown for 6 days on an orbital shaker $(120 \mathrm{rpm})$ at $25^{\circ} \mathrm{C}$. Mycelium was removed by filtration through Whatman No. 1 filter paper (Whatman International, Maidstone, England), followed by filtration through a 0.22- $\mu \mathrm{m}$-pore microbial filter (Millipore, Bedford, MA). Culture filtrate was concentrated $(\times 10)$ with a Speed-Vac device (Heto, Allerod, Denmark). As a control, sterile PB medium was concentrated by the same method.

$\beta$-1,3-Glucanase activity assays. Qualitative assays were performed on plates containing $0.5 \mathrm{M}$ 4-methylumbelliferyl $\beta$-D-glucoside (MUG), phosphate-citrate buffer (50 mM phosphate per $12 \mathrm{mM}$ citrate, $\mathrm{pH} 5.0 ; \mathrm{PCB}$ ), and $1.5 \%$ agar (MUG plates) by spotting $8-\mu \mathrm{l}$ samples on MUG plates, incubating at $37^{\circ} \mathrm{C}$ for $10 \mathrm{~min}$, and visualizing with UV illumination (Spectronics, Westbury, NY) at $302 \mathrm{~nm}$.

Quantitative assays were performed with a substrate mixture containing $0.08 \%$ (wt/vol) soluble laminarin dissolved in PCB. Enzyme solution $(10 \mu \mathrm{l})$ was mixed with substrate $(40 \mu \mathrm{l})$, and the reaction mixture was incubated at $37^{\circ} \mathrm{C}$ for $60 \mathrm{~min}$. The reaction was terminated by boiling, and the amount of glucose liberated during the reaction was determined with glucose hexokinase reagent (Sigma Chemical Co., St. Louis) according to the manufacturer's instructions. Both qualitative and quantitative analyses were repeated at least twice.

Isolation and analysis of nucleic acids. A. quisqualis genomic DNA was extracted and purified as described by Beth Din and Yarden (2). A. quisqualis was grown on PDB at $120 \mathrm{rpm}$ on an orbital shaker (New Brunswick Scientific) for 4 days at $25^{\circ} \mathrm{C}$. Mycelium was harvested by filtration through Whatman No. 1 filter paper, frozen in liquid nitrogen, and lyophilized.

DNA manipulation (digestion with restriction enzymes, Southern blot analyses) was performed as described by Sambrook et al. (14). A 2.6-kb EcoRI-XhoI fragment derived from a cDNA clone that encoded an exo- $\beta$-1,3-glucanase of $C$. carbonum was separated electrophoretically in agarose gel and excised. The fragment was labeled with $\left[\alpha-{ }^{32} \mathrm{P}\right] \mathrm{dCTP}$ (Amersham International, Little Chalfont, England) with a Prime-a-Gene system, random-priming labeling kit (Promega, Madison, WI) in a total volume of $50 \mu \mathrm{l}$. Unincorporated nucleotides were removed by chromatography on a Sephadex G-50 column (Pharmacia Biotech, Uppsala, Sweden). After digestion of $A$. quisqualis genomic DNA with various restriction endonucleases, DNA samples were resolved on $1 \%$ agarose gels and blotted on nylon membranes (Magnacharge NT, Micron Separations Inc., Westborough, MA), followed by Southern blot analysis. Hybridization was performed at $42^{\circ} \mathrm{C}$ in the presence of $35 \%$ formamide, $6 \times \mathrm{SSC}(1 \times \mathrm{SSC}$ is $0.15 \mathrm{M}$ sodium chloride plus $0.015 \mathrm{M}$ sodium citrate, $\mathrm{pH} 7.0), 5 \times$ Denhardt's solution, $0.5 \%$ sodium dodecyl sulfate (SDS), and $100 \mu \mathrm{g}$ of denatured salmon sperm
DNA per ml. Final membrane washes were at $42^{\circ} \mathrm{C}$ with a solution containing $1 \times$ SSC and $0.25 \%$ SDS. The radioactive signal on membranes was visualized either by autoradiography or scanning with a bioimaging analyzer (BAS1000, Fuji, Tokyo).

DNA was sequenced with Taq FS DNA polymerase and fluorescent-dideoxy terminators by a cycle-sequencing method. The resultant DNA fragments were electrophoresed and analyzed with an automated DNA sequencer (Model 373A, Applied Biosystems, Foster City, CA). Sequencing was performed at the W. M. Keck facility, Yale University (New Haven, CT).

To extract RNA, mycelium from a liquid culture of $A$. quisqualis was harvested by filtration through filter paper (Whatman No. 1) and frozen in liquid nitrogen. Total RNA was isolated by $\mathrm{LiCl}$ precipitation (16). Poly(A) ${ }^{+}$RNA was purified by PolyATtract mRNA Isolation System IV (Promega).

RNA separation and blotting were performed according to Beth Din and Yarden (2). Total RNA (3 to $5 \mu \mathrm{l}$ ) was resolved on formamide gels and subsequently blotted on nylon membranes (Magnacharge NT). Prehybrization and hybridization were performed at $42^{\circ} \mathrm{C}$ in $5 \times \mathrm{SSC}, 50 \%$ formamide, $2 \times$ Denhart's solution, $1 \%$ SDS, $50 \mathrm{mM}$ sodium phosphate buffer $(\mathrm{pH} 6.5), 100 \mu \mathrm{g}$ of denatured salmon sperm DNA per ml, and $100 \mu \mathrm{g}$ of yeast tRNA per ml. A $2.8-\mathrm{kb}$ EcoRI-XhoI restriction fragment of the A. quisqualis exgA gene, which was isolated from an A. quisqualis cDNA library constructed during this study and labeled by the same procedure described for $E X G 1$, was used as a DNA probe. Final membrane washes were at $65^{\circ} \mathrm{C}$ with a solution containing $2 \times \mathrm{SSC}$ and $1 \%$ SDS.

cDNA library construction and screening. cDNA was synthesized with a cDNA synthesis kit (ZAP Express, Stratagene, La Jolla, CA) from poly(A) ${ }^{+}$RNA extracted from an 8-day-old culture of $A$. quisqualis in which significant extracellular $\beta$-1,3-glucanase activity was detected (discussed below). cDNA was ligated into the EcoRIXhoI arms of the ZAP Express vector. The library was screened by a plaque hybridization procedure (14), using C. carbonum EXG1 as a probe.

Host, S. fusca inoculation, and treatment with A. quisqualis. Cucumber plants (Cucumis sativus L. 'Dalila') were grown in a peat/vermiculite (1:2) mixture and inoculated with the powdery mildew pathogen $S$. fusca as described previously (1). A. quisqualis inoculum was prepared from a commercial formulation (AQ10, Ecogen Inc., Langhorne, PA) in a suspension of $5 \times 10^{6}$ spores per $\mathrm{ml}$. Powdery mildew-infected cucumbers (5 days after inoculation) were sprayed with the hyperparasite spore suspension and maintained at $100 \%$ relative humidity by placing pots in closed polyethylene bags. Bags were removed $24 \mathrm{~h}$ after application of $A$. quisqualis.

Scanning electron microscopy. Five days after inoculation with S. fusca, infected cucumber cotyledons were removed from plants and placed on $0.8 \%$ agar plates containing $0.4 \%$ benzimidazole (Sigma). A. quisqualis culture filtrate made from a 5-day-old PDBgrown culture was concentrated $(\times 10)$ with a Speed-Vac device (Heto), and 20- $\mu$ l drops of concentrated filtrate were placed on the upper side of infected cotyledons. As a control, concentrated PDB medium $(\times 10)$ was used. After placement of drops, plates were kept under light at $25^{\circ} \mathrm{C}$. After $24 \mathrm{~h}$, culture filtrate and control medium drops were removed with filter paper. Three-millimeter disks were cut from the cotyledons, immersed in glutaraldehyde $(3 \%, \mathrm{vol} / \mathrm{vol})$ for $1 \mathrm{~h}$ at room temperature, rinsed with $0.2 \mathrm{M}$ sodium phosphate buffer ( $\mathrm{pH} 7.2$ ), and dehydrated in a graded series of ethanol solutions (30 to 100\%). After dehydration, specimens were dried with $\mathrm{CO}_{2}$ (critical-point drying) and coated with gold, using a Polaron E-500 (Watford, England) device. Specimens were examined with a scanning electron microscope (JSM 35C, Jeol, Tokyo). The experiment was repeated twice.

In situ hybridization. Disks $1 \mathrm{~cm}$ in diameter were cut from powdery mildew-infected cucumber leaves treated with $A$. quisqualis. Infected leaves not treated with the mycoparasite were used as controls. Disks were placed in a 24-well Nunclon multidish (Nalge Nunc, Roskilde, Denmark), and the entire procedure (fixation, hy- 
bridization, and washing) was performed during gentle shaking. Disks were washed with $0.6 \mathrm{M} \mathrm{KCl}, 7 \mathrm{mM} \mathrm{Na}_{2} \mathrm{HPO}_{4}$, and $3 \mathrm{mM}$ $\mathrm{NaH}_{2} \mathrm{PO}_{4}(\mathrm{PKB})$ for $20 \mathrm{~min}$ at room temperature, fixed in glutaraldehyde $(2 \%, \mathrm{vol} / \mathrm{vol}$, in $\mathrm{PKB})$ for $2 \mathrm{~h}$ at room temperature, washed with $\mathrm{PKB}$ three times for $5 \mathrm{~min}$ each at room temperature, treated with Novozyme 234 (Novo Industries, Bagsvaerd, Denmark) at $10 \mathrm{mg} / \mathrm{ml}$ in $\mathrm{PKB}$ for $30 \mathrm{~min}$ at $30^{\circ} \mathrm{C}$, washed with $\mathrm{PKB}$ three times for 5 min each at room temperature, treated with proteinase $\mathrm{K}$ at $100 \mathrm{mg} / \mathrm{ml}$ in $\mathrm{PKB}$ for $20 \mathrm{~min}$ at $37^{\circ} \mathrm{C}$, washed with $\mathrm{PKB}$ three times for $5 \mathrm{~min}$ each at room temperature, fixed in glutaraldehyde $(2 \%, \mathrm{vol} / \mathrm{vol}$, in $\mathrm{PKB})$ for $20 \mathrm{~min}$ at room temperature, and washed again with $\mathrm{PKB}$ three times for $5 \mathrm{~min}$ each at room temperature.

Disks then were subjected to prehybridization ( $4 \times$ SSC, $60 \%$ formamide, $1 \times$ Denhart's solution, $0.5 \mathrm{mg}$ salmon sperm DNA per ml, and $0.25 \mathrm{mg}$ of yeast tRNA per $\mathrm{ml}$ ) at $42^{\circ} \mathrm{C}$ for $4 \mathrm{~h}$, followed by hybridization with a probe labeled by the random-priming method with a 2.8-kb EcoRI-XhoI restriction fragment of the A. quisqualis $\operatorname{exg} A$ gene with fluorored rhodamine-4-dUTP (Amersham), using a Prime-a-Gene Kit (Promega). Hybridization was performed for $20 \mathrm{~h}$ at $42^{\circ} \mathrm{C}$. After hybridization, disks were washed in a series of SSC solutions $(2 \times, 1 \times, 0.5 \times$, and $0.2 \times)$ at $42^{\circ} \mathrm{C}$ for $30 \mathrm{~min}$ at each solution strength. Samples of $S$. fusca mycelium (with or without A. quisqualis) were removed from disks for light and fluorescence microscope (Axioscop, Zeiss, Oberkochen, Germany) examination. The experiment was repeated three times.

\section{RESULTS}

exo- $\beta-1,3-G l u c a n a s e$ activity in A. quisqualis, G. roseum, and $N$. crassa culture filtrates. As a first step in analyzing the extracellular exo- $\beta$-1,3-glucanase activity in A. quisqualis, enzyme activity was determined in the filtrate of a culture growing exponentially. Glucanase activity in culture filtrate was compared with activity observed in filtrates of $N$. crassa, which is a saprophyte, and $G$. roseum, which is a mycoparasite. After 4 days, $\beta$-1,3-glucanase activity in A. quisqualis culture filtrate was $516 \mu \mathrm{mol}$ glucose liberated per h per mg dry weight, while $\beta$-1,3-glucanase activity in $N$. crassa culture filtrate was $2.77 \mu \mathrm{mol}$ glucose liberated per $\mathrm{h}$ per $\mathrm{mg}$ dry weight and in $G$. roseum was $1.74 \mu \mathrm{mol}$ glucose liberated per $\mathrm{h}$ per mg dry weight. The levels of glucanase activity in the three tests were significantly different $(P=0.05)$ according to Duncan's multiple range test. $\beta-1,3$-Glucanase activity in A. quisqualis was at least two orders of magnitude higher than in $N$. crassa and $G$. roseum.

Scanning electron microscopy. The effect of A. quisqualis culture filtrate on $S$. fusca mycelium was investigated by scanning electron microscopy (SEM). Examination of nontreated cucumber powdery mildew samples showed undamaged mycelium, conidiophores, and conidia (Fig. 1A). Examination of powdery mildew samples exposed to concentrated sterile medium revealed undamaged mycelium with unidentified sediments (Fig. 1B). It is likely, that the sediments were components of the growth medium. In contrast, examination of powdery mildew exposed to concentrated mycoparasite culture filtrate revealed mycelium that, in many instances, exhibited nonuniform external hyphal cell structures (Fig. 1C). It is possible that the observed changes in $S$. fusca hyphal structure resulted from the presence of enzymatic activity (such as cell wall-degrading enzymes) originating from the mycoparasite culture filtrate.

Isolation of the A. quisqualis $\operatorname{exg} A$ gene. A genetic approach was used to isolate a gene encoding an exo- $\beta-1,3$-glucanase from A. quisqualis. A 2.6-kbp cDNA fragment of EXGl from $C$. carbonum, a gene encoding an exo- $\beta-1,3$-glucanase (15), was used to probe for similar genes in A. quisqualis. Analysis of an A. quisqualis genomic DNA Southern blot revealed a single band in each restriction endonuclease-digested sample of genomic DNA resolved in the gel (Fig. 2), suggesting the presence of a single-copy DNA fragment resembling EXG1 in A. quisqualis.
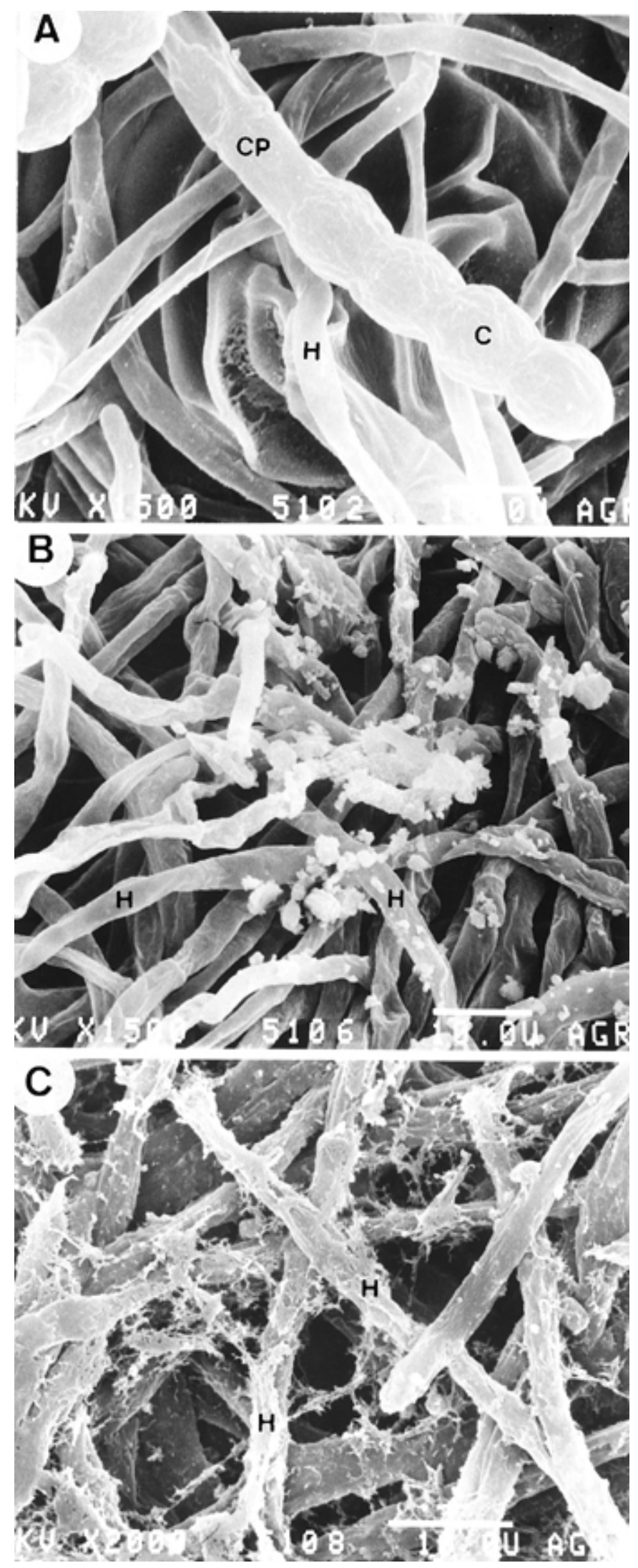

Fig. 1. Scanning electron micrographs of cucumber cotyledons infected with Sphaerotheca fusca 5 days after inoculation: A, without treatment; B, $24 \mathrm{~h}$ after exposure to a droplet of concentrated $(\times 10)$ sterile potato broth $(\mathrm{PB})$ medium; C, $24 \mathrm{~h}$ after exposure to a droplet of a concentrated $(\times 10)$ culture filtrate of Ampelomyces quisqualis (grown for 6 days on $\mathrm{PB}$ medium). $\mathrm{H}=S$. fusca hypha; $\mathrm{CP}=$ conidiophore; and $\mathrm{C}=$ conidium. 
To isolate an expressed fragment corresponding to the DNA fragment detected by Southern blot analysis, a cDNA library of A. quisqualis was constructed from poly(A) ${ }^{+}$RNA isolated from a 6-day-old culture of $A$. quisqualis. The library contained $\approx 1 \times 10^{6}$ recombinants per ml. A screen of $\approx 30,000$ plaques was performed, using the EXG1 cDNA fragment from $C$. carbonum as a probe. Five positive clones were isolated. Southern blot analysis showed that all clones had inserts of identical size, as detected by the EXGl probe. One of the clones (designated pYR-1) was used for further analysis.

DNA and deduced polypeptide sequence analysis of a putative $\beta$-1,3-glucanase-encoding gene of $\boldsymbol{A}$. quisqualis. The 2,746-bp insert of pYR-1 was sequenced completely on both strands. The comparison of the pYR-1 nucleotide sequence (GenBank accession no. AF029354) to that of C. carbonum EXG1 (provided by J. S. Craig and J. Walton, Michigan State University, East Lansing) revealed a very high degree of similarity: $61.5 \%$ identity in nucleotide sequences throughout the entire lengths of the clones. At the correct pYR-1 reading frame (determined by comparison with EXG1), the translation yielded a predicted polypeptide composed of 777 amino acids (aa). Comparison of the deduced polypeptide sequence to EXG1 showed $42.6 \%$ identity (Fig. 3). T. harzianum exo- $\beta-1,3-$ glucanase (GenBank accession no. AJ002397) also had an amino acid sequence similar to pYR-1: $46.3 \%$ identical to the predicted A. quisqualis polypeptide (Fig. 3). Two other genes that encoded nonexoglucanase sugar-degrading polypeptides also were identified in the database search: T. harzianum endo- $\beta$-1,3-glucanase (6), which was $29.6 \%$ identical to the predicted A. quisqualis polypeptide (Fig. 3), and Nicotiana sp. polygalacturonase (EMBL accession no. 322767, deposited by Tebbutt and Lonsdale [1995]), which was $24.5 \%$ identical to A. quisqualis pYR-1 (data not shown).

The high level of similarity between a single open reading frame encoded by the pYR-1 A. quisqualis cDNA clone and the deduced amino acid sequence of two fungal exo- $\beta$-1,3-glucanases suggests that the isolated $A$. quisqualis cDNA is an exo- $\beta$-1,3-glucanaseencoding gene. We designated this gene $\operatorname{exg} A$.

The presumed $\operatorname{exg} A$ start codon segment is CCATCATGCT, which is different than the putative start codon segment (CCGCTATGGC)

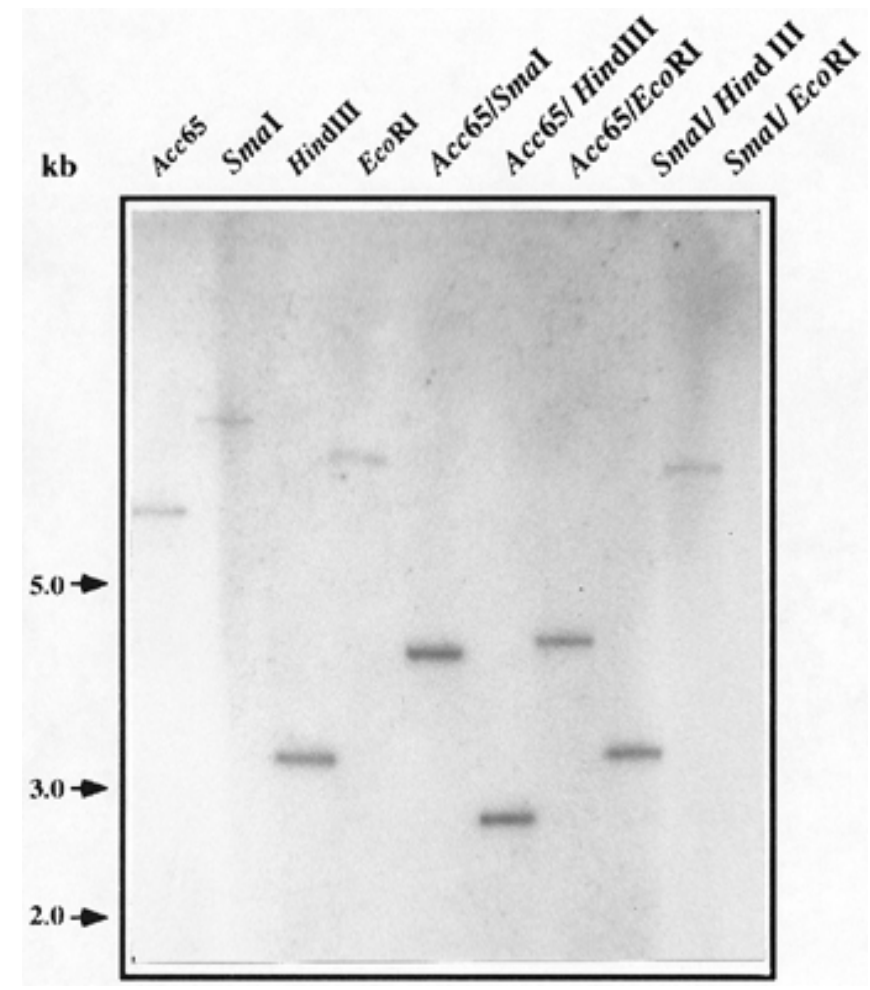

Fig. 2. Southern blot analysis of Ampelomyces quisqualis genomic DNA digested with various restriction endonucleases and probed with cDNA of Cochliobolus carbonum EXG1. Hybridization and wash conditions are described in text. of $A$. quisqualis chs $A$, the only other gene analyzed so far in $A$. quisqualis (21). Both of the presumed start codon segments show limited similarity to the translation initiation consensus found in other fungi (3). The closest match to a polyadenylation signal is AATA, at nucleotides (nt) 2728-2731 (15 nt upstream of the poly(A) tail). In comparison, the common polyadenylation signal in $N$. crassa is AATAAA, which is located 3 to $23 \mathrm{nt}$ upstream of the poly(A) tail (3).

Calculations based on the deduced amino acid sequence of $A$. quisqualis EXGA suggest the protein has a molecular mass of $84 \mathrm{kDa}$ and a pI of 4.79 . Hydrophobicity analysis of the deduced polypeptide suggests the first 40 aa create a hydrophobic region at the $\mathrm{N}$ terminus of EXGA. Similarly, the endo- $\beta$-1,3-glucanase of T. harzianum has a hydrophobic region ( $33 \mathrm{aa}$ ) at the $\mathrm{N}$ terminus, terminating with lysine and arginine. It has been suggested that this hydrophobic region may be a leader peptide that is cleaved by a KEX2-like protease at the Lys-Arg site (6). In EXGA of A. quisqualis, aa 47 and 48 are lysine and arginine, respectively. Thus, it is conceivable, based on these findings, that EXGA has a 48-aa hydrophobic leader sequence that is cleaved by a KEX2-like endoproteinase.

Comparison of a polypeptide fragment (NVAGEWSAA) of the C. albicans exo- $\beta-1,3$-glucanase activity site (11) with the EXGA amino acid sequence revealed a similar segment (NVAGETLLA) in the A. quisqualis polypeptide (aa 346-354; Fig. 3), including highly conserved (11) glutamic acid (Glu-350). Assuming functional similarity between the two glucanases exists, it is possible that the catalytic nucleophile of the enzyme may be in EXGA Glu-350.

Expression of $\operatorname{exg} \boldsymbol{A}$ in vitro. A. quisqualis culture samples from various growth stages (as well as dormant spores) were harvested. Total RNA was extracted from samples, and $4 \mu \mathrm{g}$ of RNA from each was loaded on a formaldehyde gel. Ethidium bromide staining of ribosomal RNA confirmed that total RNA quantities of all samples were similar. Northern blot results showed there was no expression of the gene in spores, and there was low transcript abundance after 3 days of growth and significant expression after 6 days of growth, followed by a reduction in transcript levels after 10 days of growth (Fig. 4A). The size of the exgA transcript was calculated as $\approx 3 \mathrm{~kb}$, based on comparison with the known sizes of $N$. crassa and A. quisqualis ribosomal RNA. The calculated size agrees with the length of the isolated $\operatorname{exg} A$ cDNA fragment (pYR-1).

The effect of dried fungal mycelium in growth medium on expression of $\operatorname{exgA}$ was analyzed. Dried $N$. crassa mycelium was added to liquid cultures of $A$. quisqualis $24 \mathrm{~h}$ prior to harvesting. Total RNA was extracted, and glucanase activity in culture filtrates was measured. Analysis of Northern blots indicated no expression of $\operatorname{exgA}$ at 3 days of growth without dried mycelium. However, at the same stage in cultures amended with dried mycelium, a distinct band that indicated gene expression was observed (Fig. 4B). Even after 6 days of growth, exgA expression in control medium was much lower than that measured after 3 days in dried mycelium-amended culture. After 6 days of growth in cultures amended with dried fungal mycelium, exgA expression had markedly increased compared with levels found in unamended culture. We concluded that $\operatorname{exg} A$ is expressed in vitro mainly in growing mycelium of $A$. quisqualis prior to pycnidia formation and that $\operatorname{exg} A$ expression is enhanced by the presence of fungal cell wall components.

Expression of $\operatorname{exg} \boldsymbol{A}$ in vivo. To analyze $\operatorname{exg} A$ expression in vivo, S. fusca mycelium and conidia, with or without $A$. quisqualis, were collected from infected cucumber leaves. Total RNA was extracted from samples of powdery mildew 2, 5, and 7 days after inoculation with the hyperparasite and from a sample of powdery mildew without the hyperparasite. Each sample consisted of material collected from 60 cucumber leaves. The experiment was repeated three times.

Northern blot analysis indicated the presence of $\operatorname{exg} A$ transcript in samples of powdery mildew treated with A. quisqualis 5 and 


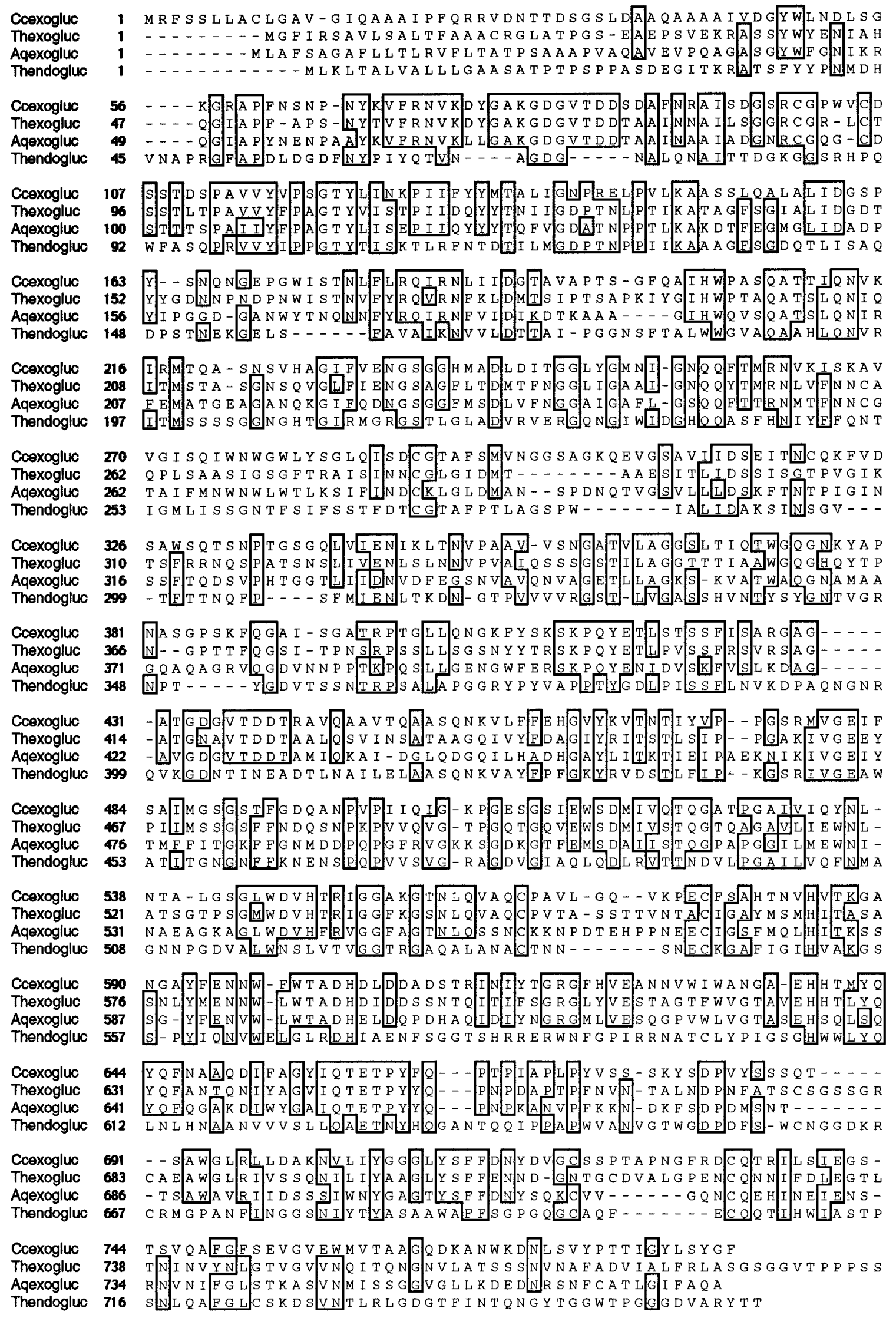

Fig. 3. Comparison of deduced amino acid sequences of Cochliobolus carbonum EXG1 (Ccexogluc), Trichoderma harzianum exo- $\beta$-1,3-glucanase (Thexogluc), Ampelomyces quisqualis putative exo- $\beta$-1,3-glucanase (Aqexogluc), and T. harzianum endo- $\beta$-1,3-glucanase BNG13.1 (Thendogluc). Dashes indicate gaps inserted for optimal alignment. T. harzianum exo- $\beta-1,3$-glucanase has a longer amino acid sequence than the other sequences presented (1,032 aa). Thus, only the section that aligns with the other glucanases is shown. 
7 days after inoculation (Fig. 4C). There was no indication of the presence of a structurally related transcript in nontreated powdery mildew and powdery mildew 2 days after treatment with $A$. quisqualis. The size of the transcript identified by the $\operatorname{exg} A$ probe was identical to the size of the transcript detected in pure A. quisqualis cultures (Fig. 4A and B).

In situ hybridization was conducted with samples obtained from a late stage of mycoparasitism (6 days after treatment with A. quisqualis). Prior to hybridization, samples of the fungi (both $S$. fusca with and without the mycoparasite from cucumber leaves and of A. quisqualis from culture) that were not subjected to hybridization with the $\operatorname{exg} A$ fluorescent probe were examined by fluorescence microscopy. None of the control samples emitted any significant signal (data not shown).

Examination of powdery mildew not treated with A. quisqualis after hybridization with the probe showed undamaged conidial chains, conidiophores, and mycelia (Fig. 5A). The signal produced by rhodamine, which indicates hybridization to the exgA probe, was very weak in the nontreated $S$. fusca conidia chain (Fig. 5B). Moreover, a relatively long image integration time $(1 / 250 \mathrm{~s})$ was required to capture the weak signal seen in this picture.

In contrast, an examination of A. quisqualis-treated S. fusca (after hybridization with the probe) showed collapsed conidia chains and conidiophores of $S$. fusca colonized by A. quisqualis (Fig. 5C and D). The rhodamine signal was intense inside the mycoparasite mycelium. A signal inside A. quisqualis pycnidia was observed that was somewhat weaker than the signal observed in the mycelia (Fig. 5E and F). A signal also was detected in pycnidiospores (Fig. 5F). In these cases (Fig. 5F), a much shorter integration time $(1 / 4,000 \mathrm{sec})$ was required to obtain the signal. The difference between the integration time required to obtain the different images, in addition to the difference in rhodamine signal, suggests hybridization of the $\operatorname{exg} A$ probe is specific to the mycoparasite and that such a gene is not expressed by $S$. fusca. The exgA gene is expressed along $A$. quisqualis mycelia (at a late stage of mycoparasitism) and, based on signal intensity, is probably expressed less in pycnidia.

\section{DISCUSSION}

The anatomy of the mycoparasitic relationship between A. quisqualis and its hosts, the Erysiphales, has been investigated and described in detail (9). However, very little is known about cellwall lytic enzymes that are produced by A. quisqualis. Our results,

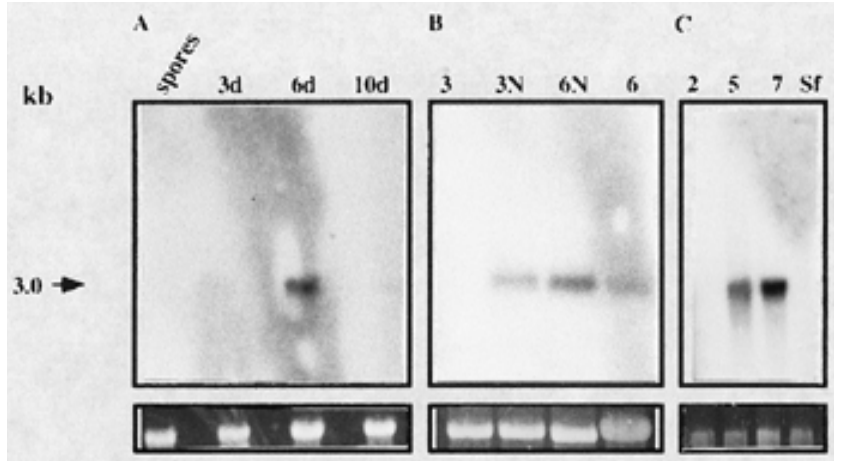

Fig. 4. Northern blot analysis of Ampelomyces quisqualis exgA expression. Blots were probed with random-primed $\left(\alpha^{32} \mathrm{P}\right) \mathrm{dCTP}$-labeled exgA. A, Samples taken from either mycelial cultures at different stages of growth (numbers indicate age, in days, of culture grown in liquid medium) or from pycnidiospores. B, Mycelial samples taken from 3- and 6-day-old liquid mediumgrown cultures, with $(\mathrm{N})$ or without added dried Neurospora crassa mycelium $(0.2 \mathrm{mg} / \mathrm{ml}) 24 \mathrm{~h}$ prior to harvesting. C, Samples extracted from Sphaerotheca fusca infected with A. quisqualis. Numbers indicate days after inoculation of S. fusca with A. quisqualis. Sf = nontreated S. fusca. Hybridization and wash conditions are described in text. Bottom panels: ethidium bromidestained rRNA, as indication of RNA loaded. with respect to the ability of $A$. quisqualis to produce extracellular exo- $\beta$-1,3-glucanase in culture compared with other fungi, suggest that these enzymes play an important role in the mechanism of mycoparasitism.

The ability of extracellular enzymes produced by mycoparasitic fungi to cause lysis of host cell walls has been demonstrated in several studies. Larena and Melgarejo (10) found that $P$. purpurogenum produces a complex of extracellular enzymes, including $\beta$ -
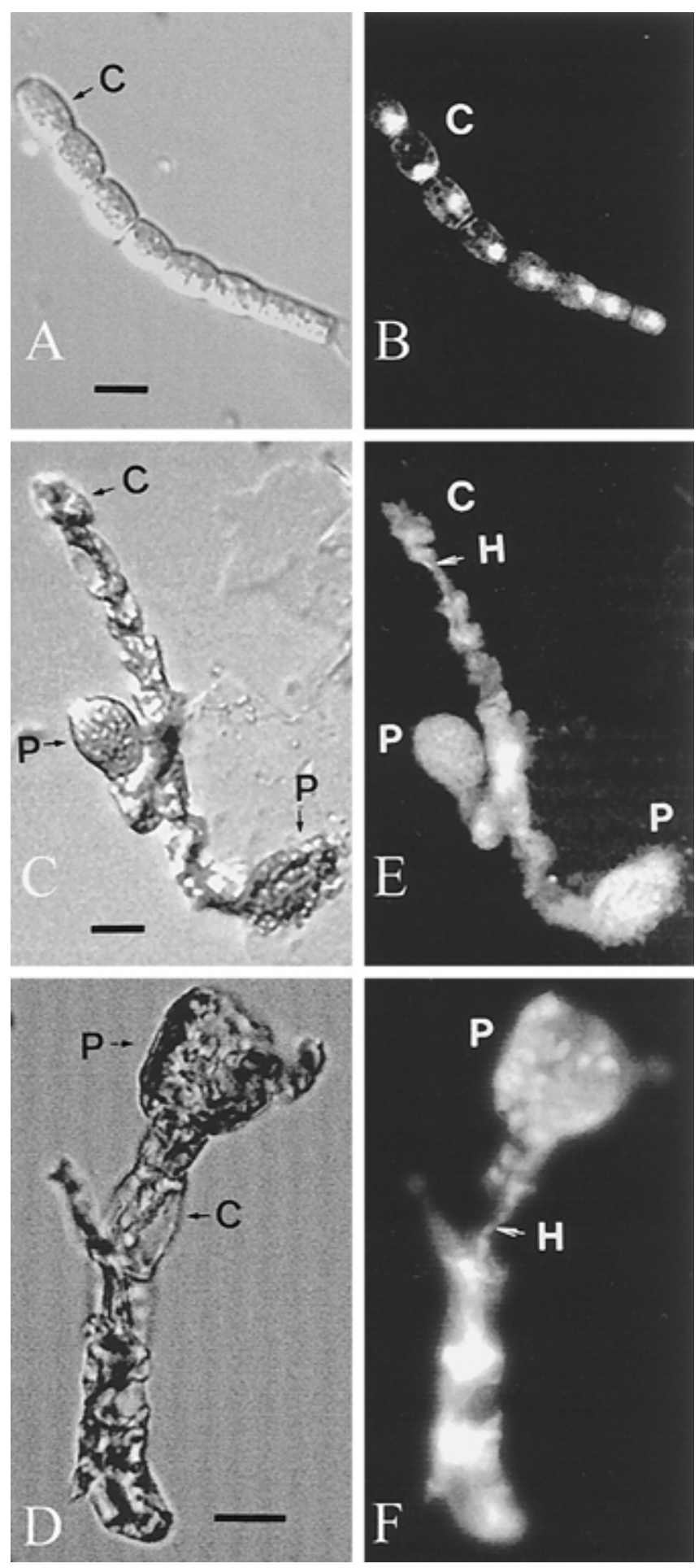

Fig. 5. In situ hybridization of Sphaerotheca fusca taken from cucumber leaves 11 days after inoculation (treated or nontreated with Ampelomyces quisqualis), probed with an $\operatorname{exg} A$ fluorescent DNA probe. A, Nontreated $S$. fusca, brightfield illumination. B, Nontreated $S$. fusca, epifluorescent illumination. C and D, A. quisqualis-treated $S$. fusca, bright-field illumination. $\mathbf{E}$ and $\mathbf{F}$, A. quisqualis-treated $S$. fusca, epifluorescent illumination. $\mathrm{C}=S$. fusca conidium, $\mathrm{P}=$ A. quisqualis pycnidium, and $\mathrm{H}=$ hypha. Bars $=10 \mu \mathrm{m}$. 
1,3-glucanase and $\beta$-1,6-glucanase, that is capable of degrading cell walls of $M$. laxa spores and mycelia. Purified $\beta$-1,3-glucanase of Stachybotrys elegans causes swelling and bursting of $R$. solani hyphal tips, cytoplasm leakage, and formation of septa in attacked hyphae (18). We found that a concentrated culture filtrate of $A$. quisqualis can cause lysis of $S$. fusca cell walls, indicating that extracellular cell wall-degrading enzymes (most likely glucanases and chitinases) of $A$. quisqualis are capable of degrading the entire host cell wall.

Reports concerning the extent of and differential roles of $\beta-1,3-$ glucanase genes and protein families are still very limited. Thus, although the presence of multiple $\beta$-1,3-glucanases in different fungi has been established $(6,13)$, their functions have yet to be determined.

It is likely that mycoparasites require additional $\beta$-1,3-glucanase activities for the mycoparasitic phase of their life cycle, in addition to the metabolic and morphogenetic $\beta$-1,3-glucanase activities that are common in other fungi. T. harzianum produces at least three extracellular $\beta$-1,3-glucanases (6). In contrast to Trichoderma spp., which are considered necrotrophic mycoparasites, A. quisqualis is a biotrophic mycoparasite (4). Because biotrophic mycoparasites tend to have different relationships with their hosts than those between necrotrophic mycoparasites and their hosts and probably a different pattern of glucanase activities, it is interesting to compare A. quisqualis and Trichoderma spp. with respect to their glucanase activities. For A. quisqualis, preliminary results of isozyme starch gel electrophoresis indicate there are at least five $\beta-1,3-$ glucanases present, and at least two are extracellular (Y. Rotem, O. Yarden, and A. Sztejnberg, unpublished data).

The $\operatorname{exg} A$ gene isolated from the A. quisqualis cDNA library is highly similar to an exo- $\beta$-1,3-glucanase gene of $T$. harzianum $(46.3 \%$ identity of deduced polypeptide sequences) and to EXG1 of $C$. carbonum ( $42.6 \%$ identity of deduced polypeptide sequences). To a lesser extent, exgA also is similar to the T. harzianum bng13.1 gene (6) that encodes an endo- $\beta$-1,3-glucanase (29.6\% identity of amino acid sequences; Fig. 3). Our analysis clearly indicates that the $\operatorname{exgA}$ gene encodes an exo- $\beta-1,3$-glucanase. It is also reasonable to assume that a gene encoding a $\beta$-1,3-glucanase would have some similarity to a gene encoding a polygalacturonase, which is another polysaccharide-degrading enzyme. Based on structural analysis, the calculated molecular mass of EXGA is $84 \mathrm{kDa}$, and its $\mathrm{pI}$ is 4.79 . According to Pitson et al. (13), fungal $\beta$-glucanases have a broad range of molecular masses, commonly ranging between 20,000 and 80,000 Da, but some fungal glucanases have molecular masses of up to $230,000 \mathrm{Da}$. In view of the broad range, a molecular mass of $84,000 \mathrm{Da}$ is not surprising. The common $\mathrm{pI}$ range of filamentous fungal $\beta$-glucanases is between 4.0 and 8.0 , and the optimal activity of fungal $\beta$-glucanases usually ranges between $\mathrm{pH} 4.0$ and 6.0. (13). Based on these glucanase enzyme properties, the A. quisqualis $\beta$-1,3-glucanase analyzed in our study has the properties of a common fungal glucanase.

Another similarity between EXGA of A. quisqualis and T. harzianum glucanases (both endo- and exo- $\beta$-1,3-glucanases) is that all have a putative hydrophobic leader sequence that ends with the amino acids Lys-Arg (6). This may indicate the presence of a leader peptide (33 aa long in T. harzianum endo- $\beta$-1,3-glucanase; 35 aa long in $T$. harzianum exo- $\beta$-1,3-glucanase; and 48 aa long in A. quisqualis glucanase) that could be cleaved by a KEX2-like endoprotease. Several secreted enzymes in Trichoderma, CHIT42 chitinase, BNG16.2 $\beta$-1,6-glucanase and PRB1 protease of T. harzianum, and XYN2 of T. reesei contain similar leader peptides (6).

Mackenzie et al. (11) identified Glu-330 as the catalytic nucleophile of $C$. albicans exo- $\beta$-1,3-glucanase. Their conclusion was based on site-directed mutagenesis. They found that glutamic acid in this position was completely conserved in this family of enzymes. A comparison of EXGA to the active site of an exo- $\beta-1,3-$ glucanase from $C$. albicans revealed a close match in EXGA amino acid sequence, which includes the glutamic acid at position 350 (Fig.
10 in Mackenzie et al. [11]). This comparison suggests that Glu350 is the catalytic nucleophile of $A$. quisqualis exo- $\beta-1,3-$ glucanase. In contrast to the findings of Mackenzie et al. (11), one notices that glutamic acid is not completely conserved in all exo$\beta$-1,3-glucanases: EXG1 of $C$. carbonum has no glutamic acid in the same position. This is true for T. harzianum BNG13.1 as well, but BNG13.1 is an endo-glucanase and, therefore, may have a different active site.

Studies on the expression of the putative $\beta$-1,3-glucanase gene in liquid culture show that the gene is expressed mainly at the stage prior to pycnidia maturation. Expression tends to be minor at the young mycelium ( 3 days old) and mature pycnidia (10 days old) stages. There is no sign of $\operatorname{exg} A$ expression in mature pycnidiospores (Fig. 4A). The results of expression studies on $S$. fusca treated with $A$. quisqualis cannot be used as an indication of the relative abundance of glucanase mRNA within the total mRNA of A. quisqualis, because we cannot distinguish between the RNA of the host and mycoparasite. Thus, it is possible that the increased abundance in $\operatorname{exg} A$ signal may be due to the proportional increase of $A$. quisqualis RNA in the mycoparasite/host RNA extract ratio, even though such a gene does not seem to be expressed in $S$. fusca. Nonetheless, our in vitro experiments support the observed appearance of $\operatorname{exg} A$ gene expression during late phases of mycoparasite development in the host.

In situ hybridization did confirm that an exgA homolog is not expressed in $S$. fusca. Our procedure also clearly demonstrated that the expression of $\operatorname{exg} A$ was located along the mycelium of $A$. quisqualis, within $S$. fusca mycelium, and during late phases of mycoparasitism when the mycoparasite forms pycnidia.

\section{ACKNOWLEDGMENTS}

We thank J. S. Craig and J. Walton, Michigan State University, for providing the EXG1 clone and sequence prior to publication, and Ecogen Israel Partnership for financial support.

\section{LITERATURE CITED}

1. Abo-Foul, S., Raskin, V. I., Sztejnberg, A., and Marder, J. B. 1996. Disruption of chlorophyll organization and function in powdery mildewdiseased cucumber leaves and its control by the hyperparasite Ampelomyces quisqualis. Phytopathology 86:195-199.

2. Beth Din, A., and Yarden, O. 1994. The Neurospora crassa chs-2 gene encodes a non-essential chitin synthase. Microbiology 140:2189-2197.

3. Bruchez, J. J. P., Eberle, J., and Russo, V. E. A. 1993. Regulatory sequences involved in the translation of Neurospora crassa mRNA: Kozak sequences and stop codons. Fungal Genet. Newsl. 40:85-88.

4. Chet, I., Inbar, J., and Hadar, Y. 1997. Fungal antagonism and mycoparasitism. Pages 165-184 in: The Mycota. Vol. 4, Environmental and Microbial Relationships. K. Esser and P. A. Lemke, eds. Springer-Verlag, Berlin.

5. Chiu, S. C., and Tzean, S. S. 1995. Glucanolytic enzyme production by Schizophyllum commune Fr. during mycoparasitism. Physiol. Mol. Plant Pathol. 46:83-94.

6. De La Cruz, J., Pintor-Toro, J. A., Benitez, T., Llobell, A., and Romero, L. C. 1995. A novel endo- $\beta$-1,3-glucanase, BNG13.1, involved in mycoparasitism of Trichoderma harzianum. J. Bacteriol. 177:6937-6945.

7. Elad, Y., Chet, I., Boyle, P., and Henis, Y. 1983. Parasitism of Trichoderma spp. on Rhizoctonia solani and Sclerotium rolfsii-Scanning electron microscopy and fluorescence microscopy. Phytopathology 73:85-88.

8. Falk, S. P., Gadoury, D. M., Cortesi, P., Pearson, R. C., and Seem, R. C. 1995. Parasitism of Uncinula necator cleistothecia by the mycoparasite Ampelomyces quisqualis. Phytopathology 85:794-800.

9. Hashioka, Y., and Nakai, Y. 1980. Ultrastructure of pycnidial development and mycoparasitism of Ampelomyces quisqualis parasitic on Erysiphales. Trans. Mycol. Soc. Jpn. 21:329-338.

10. Larena, I., and Melgarejo, P. 1993. The lytic enzymatic complex of Penicillium purpurogenum and its effects on Monilinia laxa. Mycol. Res. 97: 105-110.

11. Mackenzie, L. F., Brooke, G. S., Cutfield, J. F., Sullivan, P. A., and Withers, S. G. 1997. Identification of Glu-330 as the catalytic nucleophile of Candida albicans exo-beta-(1,3)-glucanase. J. Biol. Chem. 272:3161-3167.

12. Philipp, W. D. 1985. Extracellular enzymes and nutritional physiology of Ampelomyces quisqualis Ces., hyperparasite of powdery mildew, in vitro. 
Phytopathol. Z. 114:274-283.

13. Pitson, S. M., Seviour, R. J., and McDougall, B. M. 1993. Noncellulolytic fungal $\beta$-glucanases: Their physiology and regulation. Enzyme Microb. Technol. 15:178-192.

14. Sambrook, J., Fritsch, E. F., and Maniatis, T. 1989. Molecular Cloning: A Laboratory Manual. Cold Spring Harbor Laboratory Press, Cold Spring Harbor, NY.

15. Schaeffer, H. J., Leykam, J., and Walton, J. D. 1994. Cloning and targeted gene disruption of EXG1, encoding exo- $\beta$-1,3-glucanase, in the phytopathogenic fungus Cochliobolus carbonum. Appl. Environ. Microbiol. 60:594-598.

16. Sokolovsky, V., Kaldenhoff, R., Ricci, M., and Russo, V. E. A. 1990. Fast and reliable mini-prep RNA extraction from Neurospora crassa. Fungal Genet. Newsl. 37:41-43.

17. Sztejnberg, A., Galper, S., and Lisker, N. 1989. Conditions for pycnidial production and spore formation by Ampelomyces quisqualis. Can. J. Microbiol. 36:193-198.

18. Tweddell, R. J., Jabaji-Hare, S. H., Goetghebeur, M., Charest, P. M., and Kermasha, S. 1995. Purification and partial characterization of a $\beta-1,3-$ glucanase secreted by the mycoparasite Stachybotrys elegans. Biosci. Biotechnol. Biochem. 59:2223-2227.

19. Urquhart, E. J., Menzies, J. S., and Punja, Z. K. 1994. Growth and biological control activity of Tilletiopsis species against powdery mildew (Sphaerotheca fuliginea) on greenhouse cucumber. Phytopathology 84:341351.

20. Vogel, H. J. 1956. A convenient growth medium for Neurospora crassa (medium N). Microb. Genet. Bull. 13:42-43.

21. Weiss, N., Sztejnberg, A., and Yarden, O. 1996. The chsA gene, encoding a class-I chitin synthase from Ampelomyces quisqualis. Gene 168:99102 . 